\title{
Manners of rhotic articulation in French lyric singing
}

Uliana Kochetkova

Department of Phonetics, Saint Petersburg State University, Russia

https://doi.org/10.36505/ExLing-2018/09/0016/000349

\begin{abstract}
This study deals with the analysis of the uvular / $\mathrm{r} /$ articulation in singing. Traditionally operatic singers have been avoiding this sound because of its disturbing effect on the vowel production. However some of the modern French lyric singers pronounce this consonant in Art songs, as well as in opera. The aim of the study was to examine the manners of rhotic articulation in singing. Commercial recordings of Art songs of Gabriel Fauré performed by two French singers (a countertenor and a soprano) were analysed. The results of the study showed that both a uvular approximant and a uvular trill were produced, frequently co-occurring with an epenthetic vowel.

Key words: French phonetics, singing, uvular rhotics, consonant clusters, vowel
\end{abstract}

\section{Introduction}

Vocal speech has been considered in numerous studies, its articulatory and acoustic characteristics being of special interest for both singers and scientists. Nevertheless most of contemporary works are focused on vowels, their formant structure, notably on "singer formant" or "singer formant cluster" analysis, as well as on the voice quality and vibrato acoustic features. Consonants have not received a detailed study, whereas consonant articulation may be a challenging task for lyric singers, especially the French / r/ pronunciation.

Singers have been advised to avoid it in formal singing and to produce an alveolar $/ \mathrm{r} /$. The uvular $/ \mathrm{r} /$ has been considered as interrupting and disturbing the correct airflow in singing since the appearance of Bel Canto style onwards. However such a pronunciation is occurring in vocal speech with increasing frequency nowadays, as it was shown in the previous analysis (Kochetkova 2016). Thus the following question arises: how can contemporary French operatic singers produce a uvular consonant without embarrassing their portamento?

The hypothesis is that in the middle of the phrase an approximant may be produced in order to facilitate the articulation and avoid constriction, and at the end of the phrase a so-called "mute e" (French shwa) may appear. The aim of the current study is therefore to observe possible manners of the uvular / $\mathrm{r} /$ articulation in French Art Songs.

ExLing 2018: Proceedings of 9th Tutorial and Research Workshop on Experimental Linguistics, 28-30 August, Paris, Frannce 


\section{Material and method}

Variants of the uvular / $\mathrm{r} /$ were analysed in the singing of two French operatic singers: one male singer (countertenor) and one female singer (soprano). For this purpose commercial recordings of their interpretations of Gabriel Fauré's Art Songs were chosen: "Clair de lune" (singers C, S), "Automne" (singer C), "Après un rêve" (singer S). Audio files were then analysed and annotated manually using PRAAT software.

\section{Results}

In the studied material two variants of the uvular / $\mathrm{r} /$ were observed with almost the same frequency. The uvular approximant [r్b] (Fig. 1) occurred in $47 \%$ of cases. The voiced uvular trill [R] (Fig. 2) was produced in $50 \%$ of cases. Other variants occurred very rarely. In one case the unvoiced fricative vowel.

$[\chi]$ was produced in a coda position. In two cases $/ \mathrm{r} /$ was realized as a

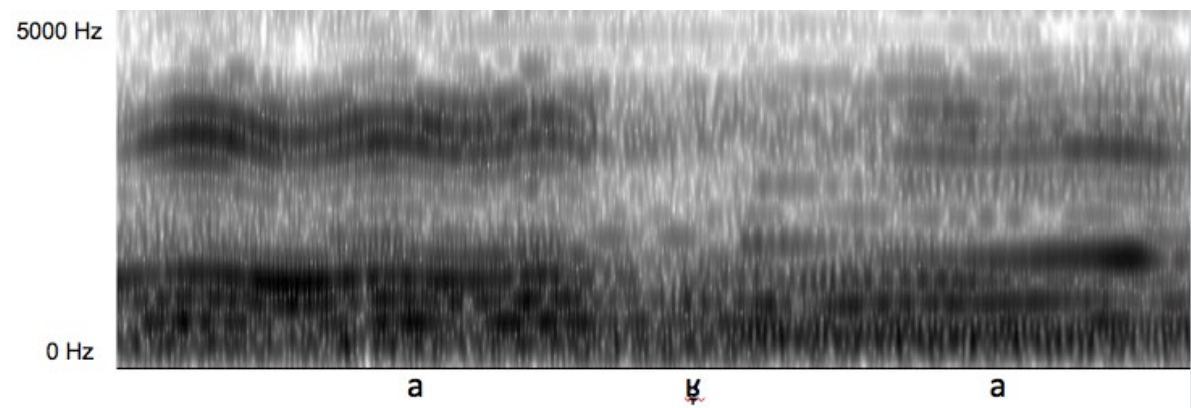

Figure 1. Uvular approximant $[\underset{T}{\mathrm{~b}}]$ in intervocalic position from croire à /krwara/, countertenor ("Clair de lune").

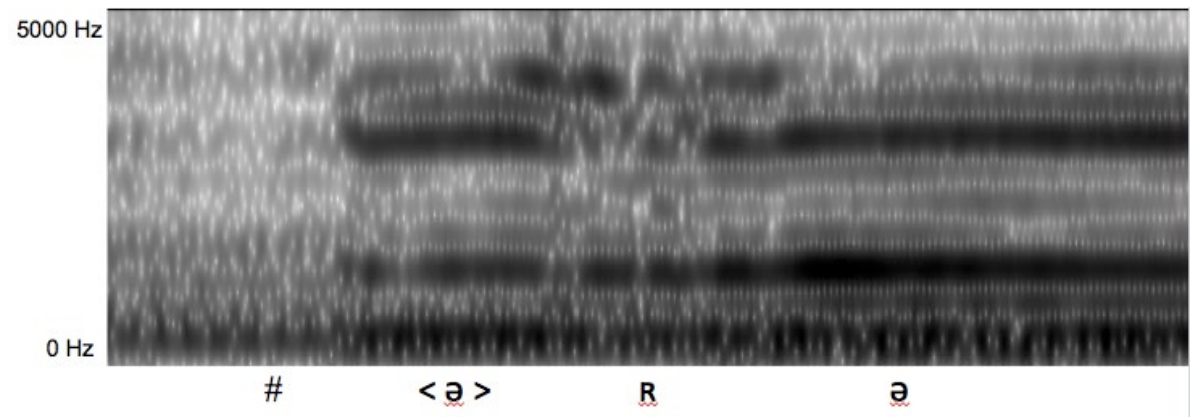

Figure 2. Uvular trill $[\mathrm{R}]$ preceded by a vowel (vocoid) from \# reviens /\#rovjẽ / (initial position), soprano ("Après un rêve"). 


\section{Uvular $/ r / s$ in various phonetic contexts}

In the texts of the chosen Art songs the following /r/-contexts occurred: $\mathrm{VrV}, \mathrm{VCrV}, \mathrm{VCCrV}, \mathrm{VCrSV}$ (between a consonant and a semi-vowel), $\mathrm{VrCrV}, \mathrm{VrCV}, \mathrm{Vr} \#$ and \#Vr. Hereafter the contexts with $/ \mathrm{r} / \mathrm{s}$ in consonant clusters were grouped into two context types: with /r/ after a consonant $(\mathrm{CrV})$ and $/ \mathrm{r} /$ before a consonant $(\mathrm{VrC})$.

As can be seen from Table 1, there was no similarity in the singers' realisations of the uvular consonant in different positions. In intervocalic positions the soprano produced mostly uvular trills $(72 \%)$, while in the countertenor's singing both uvular trill and uvular approximant occurred with almost equal frequency (see table 1).

Table 1. Occurrence of two variants of the uvular $/ \mathrm{r} /$ in different contexts.

\begin{tabular}{|l|l|l|l|}
\hline \hline Context & Singer & Uvular approximant [⿶] $]$ ] & Uvular trill [R] \\
\hline \multirow{2}{*}{$\mathrm{RrV}$} & countertenor & $53 \%$ & $47 \%$ \\
\cline { 2 - 4 } & soprano & $28 \%$ & $72 \%$ \\
\hline \multirow{2}{*}{$\mathrm{CrV}$} & countertenor & $71 \%$ & $29 \%$ \\
\cline { 2 - 4 } & soprano & $64 \%$ & $36 \%$ \\
\hline \multirow{2}{*}{$\mathrm{rCV}$} & countertenor & $25 \%$ & $75 \%$ \\
\cline { 2 - 4 } & soprano & $55 \%$ & $45 \%$ \\
\hline
\end{tabular}

It is only after a consonant that most of $/ \mathrm{r} / \mathrm{s}$ were produced as an

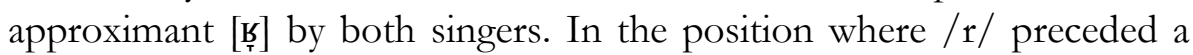
consonant, the countertenor preferred the uvular trill $[\mathrm{R}](75 \%)$, whereas the difference in occurrence of the two variants in soprano's performances was insignificant. In final and initial positions $/ \mathrm{r} / \mathrm{s}$ occurred very rarely. Summarizing both singers' realizations, the approximant was observed in 5 cases out of 7 , and the trill appeared in 2 cases out of 4.

\section{Co-occurrence of an epenthetic vowel with the uvular / $r$ /}

An epenthetic vowel or, more precisely, a vocoid according to K. Pike's terminology, proved to be a champion in co-occurrence with /r/segments. This vocoid was observed not only in consonant clusters, but also in the initial position (see Fig. 1). This vocalic segment occurred at a coda as well. In this position it could possibly be treated as a vowel, because it functioned as a "mute $\mathrm{e}$ ".

In the studied material $90 \%$ of $/ \mathrm{r} / \mathrm{s}$ in the soprano's singing and $79 \%$ of uvular consonants in the countertenor's performances were followed or preceded by a vocoid (excepting an intervocalic position). The analysis 
of $/ \mathrm{r} / \mathrm{s}$ in consonant clusters showed that both singers produced more vocoids before a consonant than in cases when $/ \mathrm{r} /$ followed the consonant. In the countertenor's performances $95 \%$ of $\mathrm{VrC}$ contexts and only $58 \%$ of $\mathrm{CrV}$ contexts contained an epenthesis. In the soprano's singing a vocoid occurred in $91 \%$ of pre-consonant positions $(\mathrm{VrC})$ and in $82 \%$ of post-consonant positions $(\mathrm{CrV})$.

\section{Conclusion}

The results of the current study show that uvular $/ \mathrm{r} / \mathrm{s}$ in singing are produced not only as an approximant, but also as a trill. It was also observed that some contexts might favor the production of one or another variant. Thus $\mathrm{CrV}$ context seems to be more favorable for the approximant realization than $\mathrm{VrC}$. The fact that no uvular fricative [ $\mathrm{b}]$ was observed in the examined material may be explained by the Aerodynamic Voicing principle formulated by J.J.Ohala (1983) and cited in the recent works on French / $\mathrm{r} /$ (Gendrot 2017). According to this principle, constriction would generally lead to the unvoicedness. It seems that singers try to avoid this unvoicedness.

The most salient feature of the uvular / $/ \mathrm{r}$ realization in the studied vocal speech is the production of a vocoid preceding or following the uvular consonant (a trill as well as an approximant). It seems to be the most important "technique" that enables singers to pronounce the uvular $/ \mathrm{r} /$. Such a realization is especially important in $\mathrm{VrC}$ structures. An additional syllable helps singers not only to maintain a correct airflow, but also to produce a uvular /r/ that can supposedly be perceived by listeners more easily, thus achieving a better intelligibility in singing.

\section{References}

Gendrot, C. 2017. Perception and production of word-final $/ \mathrm{r} /$ in French. Proc. Interspeech, 3926 - 3930, Stokcholm, Sweden.

Ladefoged, P., Maddieson, I. 1996. The Sounds of the World's Languages. Oxford: Blackwell publishers.

Kochetkova, U. 2016. Some aspects of $/ \mathrm{r} /$ articulation in French vocal speech. In Botinis, A. (Ed.), Proc. $7^{\text {th }}$ Tutorial and Research Workshop on Experimental Linguistics, 87 - 90, Saint-Petersburg, Russia.

Ohala, J.J. 1983. The origin of sound patterns in vocal tract constraints. In MacNeilage, P. (Ed.) 1983, The Production of Speech, 189 - 216. New York: Springer -Verlag.

Spreafico, L., Vietti, A. (Eds.) 2013. Rhotics. New Data and Perspectives. Bolzano: Bozen-Bolzano University Press. 